\title{
Multicenter Drug Use Evaluation of Tamsulosin and Availability of Guidance Criteria for Nonformulary Use in the Veterans Affairs Health System
}

MURIEL BURK, PharmD; ELAINE FURMAGA, PharmD; DIANE DONG, RN, MS; and FRANCESCA CUNNINGHAM, PharmD

\begin{abstract}
OBJECTIVE: The U.S. Department of Veterans Affairs (VA) Pharmacy Benefits Management Strategic Healthcare Group (PBM-SHG) and its Medical Advisory Panel developed national criteria (guidelines) for the appropriate use of tamsulosin in the VA. Drug use evaluation (DUE) was performed to (a) determine the prescribing patterns (indications and patient follow-up monitoring as measured by a clinician's note regarding evaluation of therapeutic response or report of adverse drug event) of tamsulosin, (b) assess the impact of the availability (not active dissemination) of national criteria for nonformulary use of tamsulosin, and (c) project the cost avoidance if generic terazosin was substituted for tamsulosin in those patients who were prescribed tamsulosin outside of appropriate use criteria.

METHODS: Geographically dispersed VA medical centers were identified for which tamsulosin utilization was significantly above and below the national average (4.8\% of all prescriptions for alpha [ $\alpha$ ]-blockers) in January 2001. A data collection form for medical record abstraction was designed to capture the patient's diagnosis, reported indication for tamsulosin, history of previous $\alpha$-blocker use, tamsulosin follow-up evaluation, and the individual facility's method of implementation of criteria for nonformulary use. Patients receiving a prescription for tamsulosin during a 3-month period preceding the posting of national criteria, and patients with a first-time prescription for tamsulosin during a 3-month period after the national criteria were posted were randomly selected by the PBM and assigned for chart review at each site.
\end{abstract}

RESULTS: Data for 332 patients were collected from 6 different sites over a 6-month period for each pregroup and postgroup beginning August 2001 and January 2002, respectively. Tamsulosin was prescribed for appropriate indications in $66 \%$ of patients, potentially appropriate indications in $4 \%$ of patients, and inappropriate indications in $30 \%$ of patients. of the 206 patients $(62 \%)$ who were prescribed tamsulosin as a result of a reported adverse event with a previous $\alpha$-blocker, only $29 \%$ of the cases $(\mathrm{N}=59$ ) showed evidence that an attempt was made to reduce the dose of the first $\alpha$-blocker to abate the side effects. Followup monitoring was conducted in $78 \%$ of tamsulosin patients, of whom $55 \%$ reported effectiveness of tamsulosin, and $6 \%$ reported side effects attributable to tamsulosin. No meaningful differences in prescribing patterns were found between the pregroups and postgroups relative to the posting of the criteria for nonformulary use. Two sites had some form of the criteria made available to physicians, while 4 sites had not implemented the national criteria. Extrapolation of the results to the VA system-wide yielded a conservative estimate of $\$ 480,993$ in potential cost avoidance for 1 quarter (July to September 2002) when corrected for patients prescribed tamsulosin outside of the criteria for nonformulary use.

CONCLUSIONS: Despite the availability of national criteria for nonformulary use of tamsulosin, the results reveal that these criteria were not followed by prescribers. The DUE reinforced the need for more effective implementation and dissemination of criteria for appropriate use of tamsulosin. A formal education process is necessary to encourage appropriate use of formulary $\alpha$-blockers and to attenuate the increased cost associated with the inappropriate prescribing of the nonformulary drug.

KEYWORDS: Drug use evaluation, Criteria for nonformulary use, Guidelines, Benign prostatic hyperplasia, Alpha $(\alpha)$-adrenergic antagonist, Tamsulosin

J Manag Care Pharm. 2004;10(5):423-32
T amsulosin (Flomax) is described as a selective alpha $(\alpha)_{1 \mathrm{~A}}$-adrenergic antagonist (or blocker) that has been shown to improve lower urinary tract symptoms in patients with benign prostatic hyperplasia (BPH). ${ }^{1-9}$ Other $(\alpha)$-blockers are also effective and available for treating patients with symptomatic BPH (e.g., terazosin, prazosin, doxazosin), ${ }^{10-21}$ all of which are available by generic name, at lower cost. The effectiveness of tamsulosin and other $\alpha$-blockers appear to be similar in the reduction of symptoms of BPH..$^{22}$ Information from well-designed studies to support the use of tamsulosin in patients with BPH who have not responded to an adequate trial with terazosin, prazosin, or doxazosin is lacking.

Tamsulosin differs from the other $\alpha$-blockers in selectively blocking the $\alpha$ receptors in the genitourinary area with a minimal effect on the smooth muscle vasculature. Hence, the effect of tamsulosin on blood pressure is negligible. The incidence of orthostatic hypotension has been reported to be approximately $1 \%$ with tamsulosin (and alfuzosin, a clinically uroselective $\alpha$-blocker) compared with $2 \%$ to $8 \%$ with terazosin or doxazosin in placebo-controlled studies. ${ }^{22}$ Moreover, symptomatic postural hypotension has reportedly been lower with tamsulosin (3\%) than with doxazosin (4\%) and terazosin $(6 \%, P<0.05){ }^{23}$

In addition to being effective in patients with symptomatic $\mathrm{BPH}$, the $\alpha$-blockers-terazosin, prazosin, and doxazosin-are approved for the management of patients with hypertension. In contrast to the other $\alpha$-blockers, tamsulosin is not indicated for the management of patients with hypertension. ${ }^{24}$

\section{Authors}

MURIEL BURK, PharmD, is a clinical pharmacist specialist, outcomes research; ELAINE FURMAGA, PharmD, is a clinical pharmacist specialist; DIANE DONG, $R N$, MS, is a data analyst, outcomes research; and FRANCESCA CUNNINGHAM, PharmD, is a program manager, pharmacoepidemiologic/outcomes research, VA Pharmacy Benefits Management Strategic Healthcare Group, Hines, Illinois; Cunningham is also an associate professor, College of Pharmacy, University of Mlinois at Chicago.

AUTHOR CORRESPONDENCE: Muriel Burk, PharmD, Clinical Pharmacist Specialist, Outcomes Research, VA Pharmacy Benefits Management Strategic Healthcare Group, 1st Ave., 1 Block North of Cermak Rd. Bldg. 37, Rm. 139, Hines, IL 60141. Tel: (708) 786-7881; Fax: (708) 786-7989;

E-mail:Muriel.Burk@med.va.gov

Copyright $\odot$ 2004, Academy of Managed Care Pharmacy. All rights reserved. 


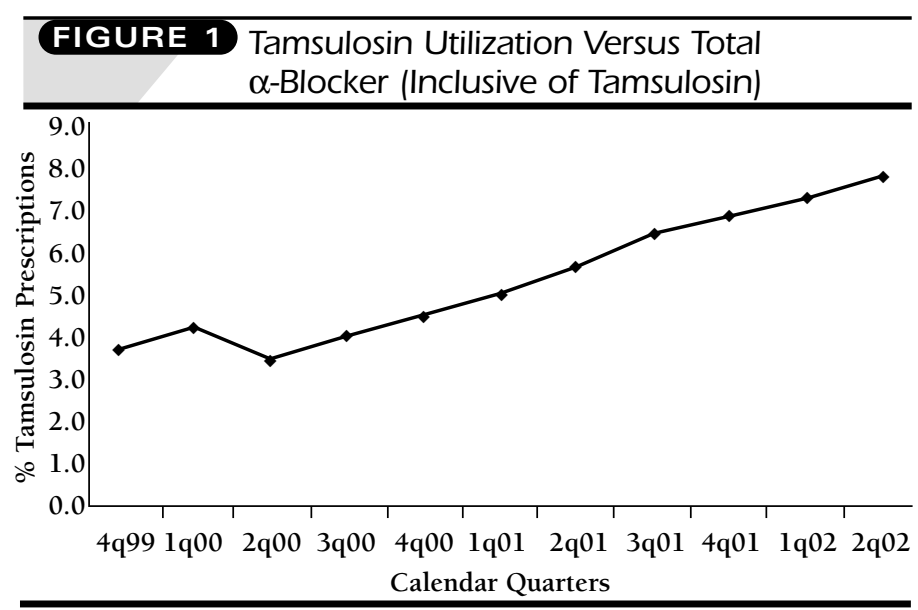

\section{FIGURE $2 \alpha$-Blocker Total Drug Cost} Based on Utilization Data*

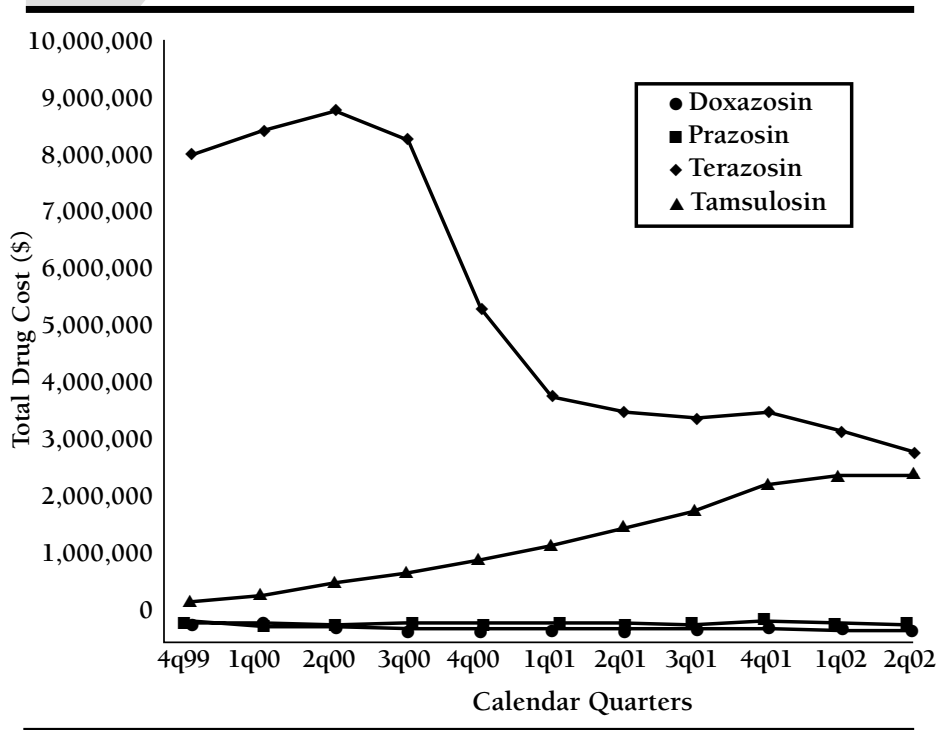

* Utilization data were used to calculate drug cost because terazosin was purchased directly from the manufacturer at the time of this study rather than from the wholesale prime vendor.

The U.S. Department of Veterans Affairs (VA) Pharmacy Benefits Management Strategic Healthcare Group (PBM-SHG) routinely monitors utilization of select drug classes or individual agents. Tamsulosin was approved by the U.S. Food and Drug Administration (FDA) on April 15, 1997 (http://www.fda.gov/cder/foi/nds/97/020579ap.pdf). The PBM-SHG began evaluating utilization of the $\alpha$-blocker class in 1997 after a national contract was awarded for terazosin. In the last quarter of 1998, VA decision makers recommended that tamsulosin be included in the monitoring of this class in view of its higher cost.

National utilization of tamsulosin more than doubled as a percentage of total $\alpha$-blocker prescriptions, from 3.7\% in the last calendar quarter of 1999 to $7.8 \%$ in the second quarter of 2002, and this has resulted in increased tamsulosin drug cost (Figures 1 and 2). To promote more uniform access and appropriate use of tamsulosin across the VA system, national criteria were developed for appropriate use in patients with BPH under selected circumstances, where symptomatic or orthostatic hypotension may be of concern.

In addition, after the discontinuation of the doxazosin treatment arm in the Antihypertensive and Lipid-Lowering Treatment to Prevent Heart Attack Trial (ALLHAT) in June $2000,{ }^{25}$ the PBM Medical Advisory Panel (PBM-MAP) developed a statement on the use of $\alpha$-adrenergic blockers for the management of patients with hypertension that was posted on the PBM Web site and disseminated through the regional pharmacy managers. The document recommended that patients should not receive monotherapy with an $\alpha$-blocker for the treatment of hypertension. Since VA patients often have a diagnosis of BPH and hypertension, recommendations on the adjustment of an $\alpha$-blocker and other antihypertensive agents were included in the national criteria (Table 1).

Specific recommendations for monitoring tamsulosin were also included in the criteria. These recommendations included monitoring for frequently reported side effects as well as less common but troublesome side effects. Optimal dosing and dose escalation recommendations were also monitored (summary of the national criteria presented in Table 1). In addition, the criteria for use of tamsulosin have since been updated to include recommendations on the use of alfuzosin, a clinically uroselective $\alpha$-blocker approved for the management of patients with symptomatic BPH.

Terazosin and prazosin were listed on the Veterans Affairs National Formulary (VANF) at the time of the evaluation, but tamsulosin and doxazosin were nonformulary drugs. Doxazosin was subsequently added to the VANF in December 2002 to provide an additional cost-effective alternative to tamsulosin. Despite the fact that tamsulosin is not on the VANF, individual facilities have the option to place it on their local formularies with or without restrictions. None of the drug use evaluation (DUE) sites in this study had added tamsulosin to their local drug formularies at the time of this study.

Obstacles to realizing the full potential of a national guidance for the appropriate use of a drug include the absence of standardized dissemination of documents from a national level to the local VA facilities and variance in the implementation methods at the facilities. Slow adoption of these guidance documents that aid providers in clinical decision making prevails for a number of reasons. These include an absence of standards in information distribution, costs, lack of leadership, 
and difficulty gaining acceptance among providers. This is a weakness in the current process employed within the VA system involving dissemination of national PBM guidance documents at the clinician level.

Guidance documents such as criteria for use and pharmacological management algorithms are typically not disseminated to clinicians. The documents are posted on the PBM Web site, and an electronic mail notification is sent to regional pharmacy managers informing them of the availability of the documents. It is then the responsibility of the individual facilities to implement the guidance documents. Thus, there is no standardized method to disseminate guidance documents and ensure their implementation. This creates an impediment to the effective and widespread implementation of these documents in clinical practice.

\section{Objectives}

A DUE was conducted in March 2001, coincident with posting of the national criteria for nonformulary use of tamsulosin on the PBM Web site (in the same month). This DUE combined with chart review was designed to (a) determine the prescribing patterns of tamsulosin, (b) assess the impact of availability of national criteria on prescribing patterns, and (c) estimate the potential cost avoidance when correcting for inappropriately prescribed patients. Secondary objectives of the evaluation were to (a) determine where tamsulosin fits in the cost-effective treatment of BPH in VA patients, (b) modify the criteria as warranted, and (c) assess the need for targeted physician education.

\section{Methods}

The PBM utilization reports identified facilities with tamsulosin utilization $50 \%$ greater than and $50 \%$ less than the national average of $4.8 \%$ of total $\alpha$-blocker prescriptions. The PBM queried 10 geographically dispersed sites ( 5 high use and 5 low use) for interest in participation in the DUE. Six sites volunteered to participate in the evaluation. Using the VANF Database PBM v.3 software, the PBM identified patients with an active prescription for tamsulosin during a 3-month period (January through March 2001) preceding the posting of national criteria and patients who received a first-time prescription for tamsulosin during a 3-month period (July through September 2001) after posting the national criteria. Posting refers to placing the document on the PBM Web site (in March 2001) with coincident electronic mail notification to all 22 regional pharmacy managers of the availability of this document on the Web site; the e-mail notification did not include a facsimile of the guidelines. Computer-generated randomsampling was used to create a list of 25 patients at each of the low-use sites and 60 patients at each of the high-use sites. Retrospective chart review was performed for each of these patients. All data collection from chart review was performed by clinical pharmacists or pharmacy residents under guidance of a clinical pharmacist preceptor.

\section{TABLE 1 Summary of PBM-MAP Guidelines for Nonformulary Use of Tamsulosin in VA Patients With Benign Prostatic Hyperplasia $(\mathrm{BPH})^{*}$}

\begin{tabular}{|c|c|}
\hline \multirow{2}{*}{$\begin{array}{l}\text { Consider Tamsulosin if } \\
\text { Patient Has or Develops } \\
\text { the Following While on a } \\
\text { VA Formulary } \alpha \text {-Blocker: }\end{array}$} & $\begin{array}{l}\text { h BPH } \\
:\end{array}$ \\
\hline & \\
\hline $\begin{array}{l}\text { - Significant symptomatic } \\
\text { hypotension } \\
\text { - Significant orthostatic or } \\
\text { postural symptoms; or at } \\
\text { baseline } \\
\text { - Syncope or near syncope } \\
\text { symptoms } \\
\text { - Significant adverse event } \\
\text { (consider } \downarrow \text { dose or trial of } \\
\text { alternate } \alpha \text {-blocker) }\end{array}$ & $\begin{array}{l}\text { agent; if symptomatic BP despite lowest dose } \\
\alpha \text {-blocker for BPH, consider change to } \\
\text { tamsulosin. } \\
\text { - Normotensive on antihypertensive regimen } \\
\text { (not including an } \alpha \text {-blocker) } \\
\text { Adjust antihypertensive treatment upon } \\
\text { initiation of a VA formulary } \alpha \text {-blocker. If the } \\
\text { patient develops symptomatic hypotension } \\
\text { despite adjustment of antihypertensive therapy, } \\
\text { tamsulosin may be considered to replace the } \\
\text { current } \alpha \text {-blocker. }\end{array}$ \\
\hline
\end{tabular}

* The complete criteria for use of tamsulosin are available at

http://www.vapbm.org/criteria/tamsulosincriteria.pdf (created January 2001).

$V A=U . S$. Department of Veterans Affairs; $B P=$ blood pressure; $H T N=$ hypertension .

\section{TABLE 2 Definition of Appropriate, Inappropriate, and Potentially Appropriate Indications for Tamsulosin}

\begin{tabular}{l|l|c}
\hline Appropriate & \multicolumn{1}{|c|}{ Inappropriate } & Potentially Appropriate \\
\hline - Prior ADE to & - Inadequate effectiveness & - Possible fall risk \\
$\begin{array}{l}\alpha \text {-blocker } \\
\text { - Baseline }\end{array}$ & with prior $\alpha$-blocker & - Failed finasteride \\
hypotension & - Unjustess of dose titration & \\
& as patient request, outside & \\
& VA Rx, or hesitation to try & \\
& $\alpha$-blocker \\
& $\begin{array}{l}\text { Absence of justification } \\
\text { from chart }\end{array}$ & \\
\hline
\end{tabular}

$\overline{A D E}=$ adverse drug event; $V A R x=$ U.S. Department of Veterans Affairs prescription.

Data collection forms were completed by the clinical pharmacists or pharmacy residents based on documentation in the medical record. The data elements collected including demographics (e.g., age, sex, data, indication for tamsulosin, previous $\alpha$-blocker use [including drug, dose, adverse events, effectiveness], adjustments in antihypertensive therapy and blood pressure), and follow-up notes on tamsulosin therapy [including dose, side effects, effectiveness up to 6 months]). The chart abstracter was prompted to respond to specific questions on adverse events such as dizziness, headache, orthostasis, and syncope as documented in the progress notes. Evaluation of effectiveness of tamsulosin was based on documentation in the progress notes. 


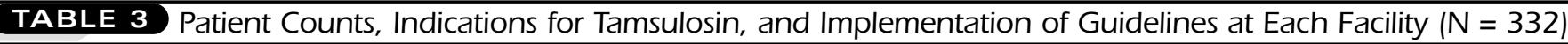

\begin{tabular}{|c|c|c|c|c|c|c|}
\hline & \multicolumn{6}{|c|}{ Medical Clinic Sites } \\
\hline & A & B & $\mathrm{C}$ & $\mathrm{D}$ & $\bar{E}$ & $\mathrm{~F}$ \\
\hline $\begin{array}{l}\text { Number of tamsulosin patients }(\mathrm{N}) \\
\% \text { tamsulosin to total } \alpha \text {-blocker patients } \\
\% \text { with concomitant BPH and HTN }(\mathrm{n}=166) \\
\text { Site defined as high or low use* } \\
\text { Criteria Implementation }\end{array}$ & $\begin{array}{r}23 \\
0.8 \\
78.3 \\
\text { Low } \\
\text { Yes }{ }^{\dagger}\end{array}$ & $\begin{array}{r}30 \\
1.0 \\
23.3 \\
\text { Low } \\
\text { Yes } ¥\end{array}$ & $\begin{array}{r}55 \\
1.9 \\
70.9 \\
\text { Low } \\
\text { No }\end{array}$ & $\begin{array}{r}39 \\
1.9 \\
7.7 \\
\text { Low } \\
\text { No }\end{array}$ & $\begin{array}{r}84 \\
8.0 \\
38.0 \\
\text { High } \\
\text { No }\end{array}$ & $\begin{array}{r}101 \\
12.1 \\
66.3 \\
\text { High } \\
\text { No }\end{array}$ \\
\hline $\begin{array}{l}\text { Appropriate indication (66\%) } \\
\% \text { ADE to } \alpha \text {-blocker§ } \\
\% \text { baseline hypotension }\end{array}$ & $\begin{array}{l}91.0 \\
11.8\end{array}$ & $\begin{array}{l}20.0 \\
20.0\end{array}$ & $\begin{array}{r}47.0 \\
5.4\end{array}$ & $\begin{array}{r}79.0 \\
0\end{array}$ & $\begin{array}{r}88.0 \\
0\end{array}$ & $\begin{array}{r}47.0 \\
7.9\end{array}$ \\
\hline $\begin{array}{l}\text { Inappropriate indication (30\%) } \\
\% \text { inadequate effectiveness with } \alpha \text {-blocker } \\
\% \text { unjustifiable reason } \\
\% \text { absence of justification in chart }\end{array}$ & $\begin{array}{r}8.7 \\
8.7 \\
0\end{array}$ & $\begin{array}{r}8.0 \\
33.3 \\
36.7\end{array}$ & $\begin{array}{l}18.2 \\
18.2 \\
16.4\end{array}$ & $\begin{array}{r}12.8 \\
5.1 \\
2.6\end{array}$ & $\begin{array}{r}0 \\
8.3 \\
13.1\end{array}$ & $\begin{array}{l}17.8 \\
18.8 \\
27.7\end{array}$ \\
\hline $\begin{array}{l}\text { Potentially appropriate indication ( } 4 \% \text { ) } \\
\% \text { possible fall risk } \\
\% \text { failed finasteride }\end{array}$ & $\begin{array}{r}0 \\
4.3\end{array}$ & $\begin{array}{l}0 \\
0\end{array}$ & $\begin{array}{l}0 \\
0\end{array}$ & $\begin{array}{l}0 \\
0\end{array}$ & $\begin{array}{l}0 \\
0\end{array}$ & $\begin{array}{r}7.9 \\
0\end{array}$ \\
\hline
\end{tabular}

* High $=>50 \%$ above national average of $4.8 \%$ tamsulosin to total $\alpha$-blocker prescriptions; low $=>50 \%$ below national average of $4.8 \%$.

+ Implemented local criteria using electronic prompts during order entry that alerts the prescriber to the criteria for appropriate use of tamsulosin.

\# Implemented national criteria using a written request form for nonformulary drug use that requires the prescriber to review the patient characteristics

against the criteria for appropriate use of tamsulosin.

$\S$ Percentages do not add up to 100 as patients may have $>1$ indication for tamsulosin.

$B P H=$ benign prostatic hyperplasia $; H T N=$ hypertension; $A D E=$ adverse drug event .

Note: Data were collected from 6 different sites over a 6-month period for each pregroup and postgroup beginning August 2001 and January 2002, respectively.

From the reported indications for tamsulosin in the chart review forms, the PBM pharmacist and DUE coordinator categorized these into appropriate, inappropriate, and potentially appropriate indications. Appropriate use was defined as having a prior adverse drug event (ADE) to an $\alpha$-blocker (regardless of whether downward dose titration was attempted) or having baseline hypotension as stated in the progress note (Table 2). Inappropriate use was defined as having inadequate effectiveness with a prior $\alpha$-blocker (regardless of dose titration), patient request for tamsulosin, outside VA prescription for tamsulosin, hesitation to try an $\alpha$-blocker because the patient's blood pressure was controlled, or inability to obtain justification from the medical chart. Potentially appropriate use was defined as the patient being at possible risk for falls, such as post-hip surgery, gait disorder, or history of falls.

Documentation forms were forwarded electronically to the DUE coordinator for analysis. Patients were assigned random ID numbers to replace Social Security numbers to conceal patient identity from study investigators.

The PBM used the percentage of inappropriately prescribed tamsulosin prescriptions to project cost avoidance for the fiscal year fourth quarter (calendar year third quarter, July through September) 2002, the most current tamsulosin utilization report available at the time. As a conservative estimate, the model did not include those patients who had inadequate effectiveness with a prior $\alpha$-blocker. Therefore, $19 \%$ instead of 30\% was used in the cost-avoidance estimate. The difference in drug cost between terazosin and tamsulosin in this group of patients was defined as the cost-avoidance opportunity.

As part of the chart review, the clinical pharmacists abstracting data at each participating site were asked to respond to the following points regarding implementation: (1) whether or not national criteria were implemented, (2) whether or not local criteria were implemented, and (3) if local or national criteria were implemented, what method was used.

Simple descriptive statistics were used to report demographics. Measures of tamsulosin prescribing were tested for significant differences using the Chi-square statistical test for pregroups and postgroups for posting of criteria as well as for the values for high- versus low-use tamsulosin sites. Fisher's exact test was used for comparison of implementation and nonimplementation sites. Institutional Review Board approval was obtained since the evaluation involved patient identifiers and patient-specific medical information. A waiver for patient consent was granted since the identity of patients was concealed from study investigators.

\section{Results}

In a convenience sampling method, 6 sites agreed to participate in the DUE, and data on 332 patients were collected from these sites (Table 3). Four sites were low-use tamsulosin sites and 2 were high-use sites, defined as $50 \%$ or greater variance from the average $4.8 \%$ of $\alpha$-blocker prescriptions for tamsulosin. High- and low-use sites were selected to assure adequate 
representation as well as to see if there were observable differences in prescribing patterns such as prescribing indications and follow-up between these sites that might justify the nonformulary use of tamsulosin. Results will be presented for the entire cohort in aggregate unless otherwise noted. All patients were male with a median age of 76 years. Slightly more than one half of these patients had a concomitant diagnosis of hypertension in addition to BPH (Table 3).

Tamsulosin was prescribed for indications defined as appropriate use in $66 \%$ of patients, potentially appropriate use in $4 \%$ of patients, and inappropriate use in $30 \%$ of patients (Table 3). Included in the definition of appropriate indication were patients who were prescribed tamsulosin due to an ADE with their original $\alpha$-blocker. This occurred in 62\% (206) of patients. Of those 206 patients, only 59 (28.6\%) patient records showed documentation of an attempt to titrate down the dose of the $\alpha$-blocker before switching to tamsulosin. The average terazosin dose for these patients was $4.5 \mathrm{mg}$, with almost one fourth of those patients on $\geq 10 \mathrm{mg}$ per day of terazosin.

The definition of inappropriate indication included (a) 37 (11.1\%) patients who had inadequate effectiveness with a prior $\alpha$-blocker (accounting for $37 \%$ of the inappropriate indications); (b) 34 (10.2\%) patients who lacked a justifiable indication for tamsulosin such as patient request, prescription from private physician, hesitation to use an $\alpha$-blocker other than tamsulosin due to adequately controlled blood pressure as noted in the provider's progress notes or to avoid potential side effects from an $\alpha$-blocker (accounting for 34\% of the inappropriate indications); or (c) 50 (15.1\%) patients with the absence of documentation (accounting for $50 \%$ of the inappropriate indications). The average final terazosin dose was $4.7 \mathrm{mg}$, and the average length of trial with the $\alpha$-blocker was 11.2 weeks for patients who were prescribed tamsulosin due to inadequate effectiveness with the original $\alpha$-blocker.

Assessment of follow-up as documented in the patient's medical record was carried out for up to 6 months. Follow-up evaluation was performed in 259 (78\%) patients, of which 44\% (114) had a first follow-up at 3 months or later and 56\% $(\mathrm{N}=145)$ received the first follow-up evaluation at less than 3 months (Table 4). Fifty-five percent $(\mathrm{N}=143)$ of patients reported effectiveness of tamsulosin, and 16 (6.2\%) reported side effects attributed to tamsulosin. Six percent of the patients who received follow-up were on the higher dose $(0.8 \mathrm{mg})$ of tamsulosin. One fourth (25.1\%) of those with follow-up evaluation were not assessed for effectiveness of tamsulosin. Tamsulosin therapy was discontinued in $14 \%$ of patients. The data collection forms of $6(2 \%)$ patients with follow-up evaluation did not indicate whether or not their tamsulosin therapy was continued. Of the 259 patients evaluated at followup, 217 (84\%) patients were continued on tamsulosin therapy. Of the 217 patients who were continued on tamsulosin, $32(14.7 \%)$ reported that tamsulosin was not effective, 7 (3.2\%)

\begin{tabular}{|c|c|c|c|}
\hline \multicolumn{2}{|c|}{ ime to first follow-up } & \multicolumn{2}{|l|}{ Side effects } \\
\hline - $<3$ months & $56.0 \%(145)$ & - Yes & $6.2 \%(16)$ \\
\hline$\cdot \geq 3$ months & $44.0 \%(114)$ & - No & $57.1 \%(148)$ \\
\hline \multicolumn{2}{|l|}{ ffectiveness } & - Not assessed & $36.7 \%(95)$ \\
\hline - Yes & $55.2 \%(143)$ & \multicolumn{2}{|c|}{ Continued tamsulosin } \\
\hline - No & $19.7 \%(51)$ & - Yes & $83.8 \%(217)$ \\
\hline - Not assessed & $25.1 \%(65)$ & - No & $13.9 \%(36)$ \\
\hline & & - Not reported & $2.3 \%(6)$ \\
\hline
\end{tabular}

\begin{tabular}{|c|c|c|}
\hline TABLE 5 & at & Tamsulosir \\
\hline $\begin{array}{l}\text { Effective } \\
\text { - Yes } \\
\text { - No } \\
\text { - Not assessed }\end{array}$ & $\begin{array}{rr}62.2 \% & (135) \\
14.7 \% & (32) \\
23.0 \% & (50)\end{array}$ & $\begin{array}{l}\text { Treatment } \\
\begin{array}{lrr}\text { - Same dose } & 81.6 \% & (177) \\
\text { - Increase dose } & 17.0 \% & (37) \\
\text { - Add finasteride } & 1.4 \% & (3)\end{array}\end{array}$ \\
\hline $\begin{array}{l}\text { Side effects } \\
\text { - Yes } \\
\text { - No } \\
\text { - Not assessed }\end{array}$ & $\begin{array}{rr}3.2 \% & (7) \\
62.7 \% & (136) \\
34.1 \% & (74)\end{array}$ & \\
\hline
\end{tabular}

reported side effects, and 74 (34.1\%) were not evaluated for side effects. Of patients who were continued on tamsulosin, 17\% had their dose increased (Table 5).

There were no significant differences in prescribing patterns between precriteria and postcriteria groups (Table 6). Of the appropriate indications for tamsulosin, ADE to prior $\boldsymbol{\alpha}$-blocker was the most commonly documented in $63.7 \%$ of patients in the precriteria group and similarly $59.5 \%$ in the postcriteria group $(P=0.45)$. Baseline hypotension (another appropriate indication) was the prescribing reason in $4.5 \%$ of patients in the precriteria group and similarly $3 \%$ in the postcriteria group $(P=0.51)$. Of the inappropriate indications for tamsulosin, inadequate effectiveness with a prior $\alpha$-blocker was the indication in 10\% of the precriteria group and similarly $13 \%$ of the postcriteria group $(P=0.39)$. Unjustifiable reasons such as patient request, prescription from private physician, and hesitation to try $\alpha$-blockers were the indications in $8.4 \%$ of the precriteria group and $13 \%$ of the postcriteria group $(P=0.18)$. Justification for the use of tamsulosin was absent from the patient medical records in $16.4 \%$ of the precriteria group and $13 \%$ of the postcriteria group $(P=0.39)$. No differences in the indications were noted when the analysis was performed for the high-use versus low-use sites except for one finding that showed that low sites had a higher percentage of unjustifiable reasons (Table 6).

Implementation information for each site was also collected as part of the DUE. Two of the 4 low-use sites responded that criteria for use, whether local or national, were implemented. 


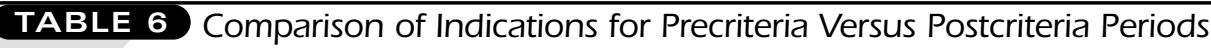
and Sites with High Versus Low Tamsulosin Use

\begin{tabular}{|c|c|c|c|c|c|c|}
\hline Indication* & Precriteria & Postcriteria & $P$ Value & $\operatorname{High} \dagger$ & Low & $P$ Value \\
\hline Number of patients (n) & 201 & 131 & & 185 & 147 & \\
\hline $\begin{array}{l}\text { Appropriate indication } \\
\% \text { ADE to } \alpha \text {-blocker (206) } \\
\% \text { Baseline hypotension (13) }\end{array}$ & $\begin{array}{r}63.7 \\
4.5\end{array}$ & $\begin{array}{l}59.5 \\
3.0\end{array}$ & $\begin{array}{l}0.45 \\
0.51\end{array}$ & $\begin{array}{c}65.9 \\
3.8\end{array}$ & $\begin{array}{r}57.1 \\
4.1\end{array}$ & $\begin{array}{l}0.10 \\
0.91\end{array}$ \\
\hline $\begin{array}{l}\text { Inappropriate indication } \neq \\
\% \text { inadequate effectiveness } \\
\text { with } \alpha \text {-blocker }(37) \\
\% \text { unjustifiable reason }(34) \\
\% \text { absence of justification }(50)\end{array}$ & $\begin{array}{l}10.0 \\
8.4 \\
16.4\end{array}$ & $\begin{array}{l}13.0 \\
13.0 \\
13.0\end{array}$ & $\begin{array}{l}0.39 \\
0.18 \\
0.39\end{array}$ & $\begin{array}{l}9.7 \\
6.5 \\
14.6\end{array}$ & $\begin{array}{l}12.9 \\
15.0 \\
15.6\end{array}$ & $\begin{array}{l}0.36 \\
0.01 \\
0.79\end{array}$ \\
\hline
\end{tabular}

* Percentages do not add up to 100 as patients may have $>1$ indication for tamsulosin.

+ High $=>50 \%$ above national average of $4.8 \%$; low $=>50 \%$ below national average of $4.8 \%$.

$¥$ Chi-square comparisons for the Potentially Appropriate Indications were not calculated due to absence of sufficient data.

$A D E=$ adverse drug event.

\begin{tabular}{|c|c|c|c|c|}
\hline ndication* & $\begin{array}{c}\text { No. of } \\
\text { Patients }\end{array}$ & $\begin{array}{c}\text { Implemented } \dagger \\
\%(\mathrm{~N})\end{array}$ & $\begin{array}{c}\text { Not } \\
\text { Implemented } \\
\%(\mathrm{~N})\end{array}$ & $P$ Value \\
\hline ppropriate indication & & & & \\
\hline $\begin{array}{l}\text { Baseline hypotension } \\
\text { nappropriate indication }\end{array}$ & 4 & $9.1(1)$ & $2.5(3)$ & 1.00 \\
\hline $\begin{array}{l}\text { Inadequate effectiveness } \\
\text { with } \alpha \text {-blocker }\end{array}$ & 17 & $9.1(1)$ & $13.3(16)$ & 1.00 \\
\hline Jnjustifiable reason & 17 & $9.1(1)$ & $13.3(16)$ & 1.00 \\
\hline Ibsence of justification & 17 & $9.1(1)$ & $13.3(16)$ & 1.00 \\
\hline
\end{tabular}

* Percentages do not add up to 100 since patients may have $>1$ indication for tamsulosin.

+ Implementation of criteria means that there is some form of check system that reviews if the patient meets criteria to have tamsulosin prescribed.

$A D E=$ adverse drug event

The site (B, Table 3) that implemented national criteria provided written forms for prescribers to complete for each patient prescribed tamsulosin, and the other site (A) that implemented local criteria incorporated computerized pop-up windows that displayed the criteria upon computer order entry of each tamsulosin prescription. We did not determine to what extent the local criteria differed from national criteria. Four sites (2 low use and 2 high use) had not implemented any criteria for nonformulary use of tamsulosin (Table 3). A comparison of indications for the sites that implemented the criteria versus those that did not implement criteria revealed that there were no significant differences in the incidence of appropriate use of tamsulosin (Table 7).

Extrapolation of the results to the entire VA system produced an estimated cost-avoidance opportunity of $\$ 480,993$ for the 3-month period from July through September 2002 if patients who were prescribed tamsulosin outside of the national criteria were prescribed terazosin instead. Patients who experienced inadequate effectiveness with their original $\alpha$-blocker were excluded in this calculation to provide a conservative estimate of the cost-avoidance opportunity. If this patient group were included, the cost-avoidance opportunity would increase to $\$ 759,462$. The annualized cost-avoidance opportunity would be in the range of $\$ 1.92$ to $\$ 3.04$ million if terazosin was used in place of tamsulosin in the VA system.

\section{Discussion}

Although the majority of patients in the DUE were prescribed tamsulosin according to national criteria, a large proportion (30\%) of patients did not meet appropriate-use criteria. Only $78 \%$ of patients who received prescriptions for tamsulosin also received follow-up assessments during the 4-to-6-month evaluation. Failure to achieve an increase in compliance with criteria may, in part, be due to the delay in implementation of the drug use criteria at the facility level.

It is difficult to provide an explanation for why low-use sites had higher rates of unjustifiable reasons such as patient requests and physician hesitance in using nonselective $\alpha$-blockers. It is our observation that the low use is not attributed to the availability of criteria for appropriate use. Additionally, it confirms that even when utilization is low, inappropriate use of tamsulosin still occurs, and sites, whether low or high use, can benefit from better education on appropriate use.

The most frequent reason for prescribing tamsulosin was an ADE with another $\alpha$-blocker. In the majority of these patients $(71.4 \%)$, there was no documentation in the medical chart that an attempt was made to adjust the dose of the first $\alpha$-blocker prior to prescribing tamsulosin. Among several possible reasons for this omission is the possibility that prescribers may avoid the nonselective $\alpha$-blockers in patients who are frail or elderly due to concerns about potential falls, despite the lack of 
evidence to support tamsulosin over other $\alpha$-blockers in these patients. The concern with fall-related costs may also be a factor; medical costs associated with falls are largely due to hip fractures, which occur in approximately $1 \%$ of falls. ${ }^{26}$ Another practical reason that prescribers might avoid the nonselective $\alpha$-blockers is attributable to physical and time constraints and the added time and resources involved in dose titration and follow-up evaluations of side effects, which should be weighed against the direct cost of these drugs.

Although the data to support the use of tamsulosin in a patient who has not responded to another $\alpha$-blocker for BPH symptoms is lacking, the results of this evaluation showed that $11 \%$ of patients were prescribed tamsulosin for this reason. We did not collect the clinical data to determine whether tamsulosin was effective in reducing BPH symptoms in patients who did not respond to a previous $\alpha$-blocker.

Since tamsulosin has minimal blood pressure-lowering effects, it may often be used as a desirable alternative to manage patients with coincident $\mathrm{BPH}$ and hypertension by eliminating the need for adjustments in antihypertensive medications or to avoid unwanted reductions in blood pressure. However, given that the VA patient with hypertension is prescribed an average of 2 antihypertensive medications, it would seem prudent to utilize the blood pressure-lowering effects of a first-line $\alpha$-blocker (prazosin, doxazosin, or terazosin) and potentially reduce the total number of drugs used to treat patients with PBH and hypertension. In this study, 53\% $(\mathrm{N}=166)$ of the patients receiving tamsulosin had concomitant diagnoses of BPH and hypertension (Table 3). Thus, the potential exists that these patients would benefit from the therapeutic effects of the traditional $\alpha$-blockers on both BPH and hypertension. This evaluation was unable to determine whether adjustment of antihypertensive therapy was warranted prior to prescribing tamsulosin in patients with concomitant hypertension.

The follow-up monitoring of tamsulosin therapy was also not optimal. One fourth of the patients had their first evaluation at a medical visit that occurred more than 3 months after initiation of tamsulosin therapy (Figure 3). Moreover, a large number of these patients (25.1\%) were not assessed for effectiveness of their tamsulosin therapy during their follow-up visit, while many (14.7\%) continued to stay on tamsulosin despite reporting that it was ineffective (Table 4).

It appears that simply making available to providers the national criteria for use via posting on an Internet Web site, with electronic mail notification, is not sufficient to influence adoption and implementation of these guidelines. The incidence of appropriate prescribing of tamsulosin was not significantly different in the period following posting of the drug use criteria compared with the period prior to posting of the criteria for appropriate use. Successful implementation of criteria for nonformulary drug use would appear to require multiple interventions to influence prescribing behavior.
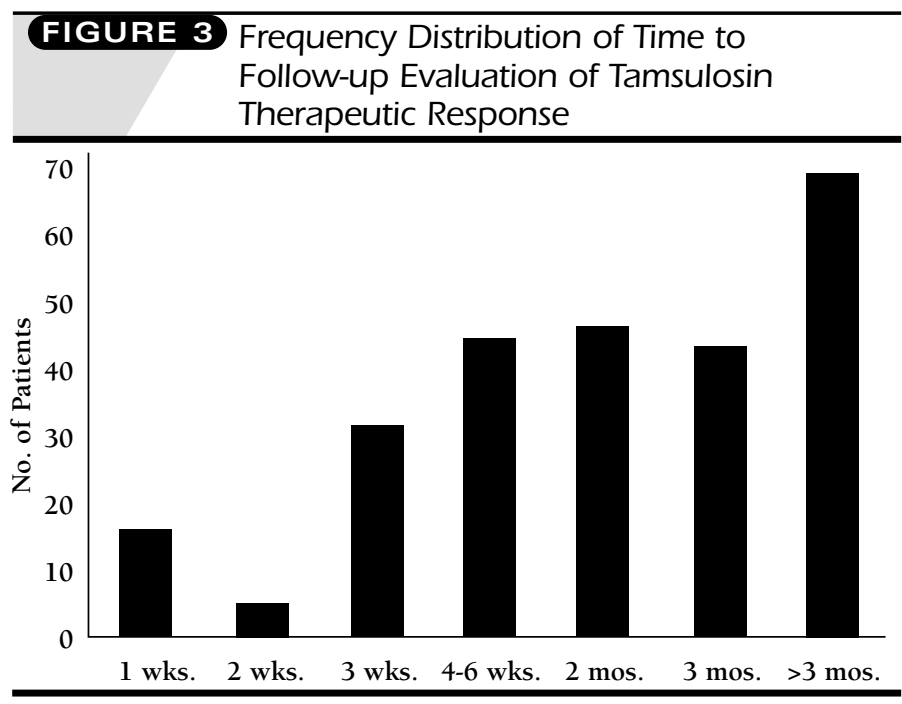

Studies have shown that just one avenue of implementation is not effective in significantly improving the incidence of appropriate prescribing; cognitive processing in the form of active discussion results in more enduring attitude changes compared with passive education. ${ }^{27-29}$ A Cochrane Database review on interventions for improving diabetes management in the primary care setting suggests that a multifaceted intervention approach can enhance effective diabetes disease management. ${ }^{30}$ Another option to encourage awareness and utilization of a national drug use guidance would be to generate prescriber-specific profiles as a mechanism to promote quality improvement by informing payers or encouraging providers to focus on quality improvement opportunities. ${ }^{31}$

Thirty percent of patients in this evaluation were prescribed tamsulosin for reasons judged to be inappropriate, with unfavorable cost implications and potentially unfavorable clinical implications. Our conservative estimate of the costavoidance opportunity, excluding patients who were prescribed tamsulosin due to reported inadequate effectiveness with another $\alpha$-blocker, translated into a system cost waste of $\$ 480,993$ for just 3 months of therapy. Furthermore, since tamsulosin is available only in the $0.4 \mathrm{mg}$ capsule, the higher dose of $0.8 \mathrm{mg}$ doubles the cost per day of therapy and may increase the potential for ADEs. As a result, a formal recommendation was made for the local facilities to evaluate the safety and effectiveness of patients on $0.8 \mathrm{mg}$ of tamsulosin.

This study showed that the simple availability of national criteria with prescribing guidelines did not appear to have a significant impact on prescriber behavior. This is a limitation that exists within the VA system in which guidance documents such as criteria for use and pharmacological management algorithms are not uniformly disseminated to all clinicians. Our evaluation confirms this weakness. The lack of a standardized 


\section{FIGURE 4 Computerized Criteria Prompts}

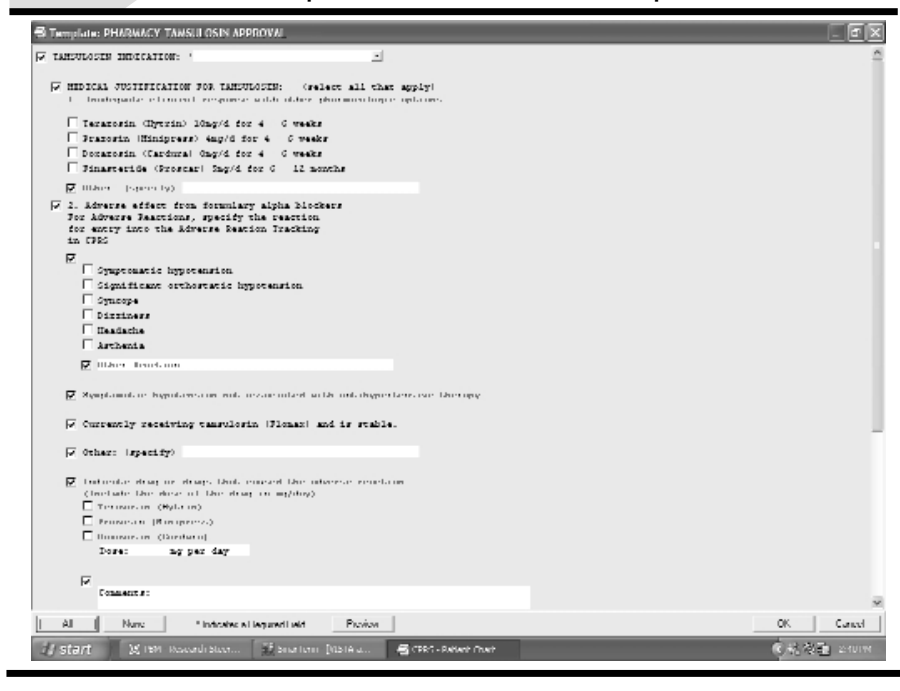

method for disseminating guidance documents creates an impediment to the effective implementation of these documents in clinical practice.

Provider education is a potentially useful tool to improve patient care and can be divided into dissemination strategies for guidelines to increase awareness and knowledge via an interactive media to put the acquired knowledge into practice. Due to the small number of sites, we were not able to assess the relative merits of the alternate methods of implementation of the criteria for nonformulary use of tamsulosin. The DUE prompted a post hoc follow-up survey that was e-mailed on January 28, 2003, to all 22 VA regional pharmacy managers across the nation requesting information on availability of criteria for nonformulary use of tamsulosin and the method of criteria implementation in each facility within their region in order to assess the effectiveness of methods of criteria implementation. Of the $140 \mathrm{VA}$ medical centers under the management of these 22 formulary leaders, there was a 55\% (77 of 140) response rate. Since the survey was conducted 2 years after the criteria were made available, sites would have had sufficient time to have implementation strategies in place.

Sites that used prescriber education as a method of implementation had an average tamsulosin utilization of $8 \%$ based on number of 30-day tamsulosin prescriptions versus all $\alpha$-blocker prescriptions, compared with pharmacy education $(9.7 \%, P=0.69)$ or having the information available in the form of a newsletter, poster, or pocket card $(9.2 \%, P=0.76)$. Sites that used computerized criteria had an average utilization of $9.9 \%$ versus $7.5 \%$ at sites that did not use computerized criteria $(P=0.56)$. Prescriber education involved educational presentations given to prescribers (e.g., internists or urologists) by pharmacists. Pharmacy education involved educational presentations given to the pharmacy staff. Computerized criteria entailed having the criteria available electronically as prompts during prescription entry alerting the prescriber to tamsulosin criteria for use (Figure 4).

This post hoc survey showed that sites that utilized prescriber education as an implementation method had a lower tamsulosin utilization rate compared with sites that used pharmacy education, newsletters, posters, or pocket cards as implementation tools. Sites that used computerized criteria alone as the method of implementation appeared to have higher tamsulosin utilization. These results were not sufficiently robust, however, to draw conclusions about the most effective means for guideline implementation.

Tailoring the method of implementation may aid in the promotion of criteria for nonformulary use. From the results of the national survey that followed the DUE, targeted education to the prescriber appears to be necessary to promote use of tamsulosin that is consistent with appropriate-use criteria. The results of this DUE helped to draw more attention to the methods for the dissemination of national guidance documents through newsletters targeted at key decision and frontline groups, prescriber profile feedback, and clinical satellite education programs tailored to be consistent with national guidance documents. The PBM is also researching methods to provide education toolkits employing various media such as pocket cards, educational CD-ROMs, PowerPoint presentation slides, and Web-based continuing education specifically designed to facilitate implementation, at the local level, of the national criteria for nonformulary use of drugs. A list-serve with all VA clinical pharmacists' e-mails in one mail-group has been created to permit such documents to be sent directly to practicing clinicians.

Adherence to the criteria may be improved by emphasis on the selected circumstances where tamsulosin may be considered and on recommendations for dose adjustment of the formulary $\alpha$-blockers, when appropriate, to minimize ADEs before prescribing tamsulosin. The additional antihypertensive benefit of the formulary $\alpha$-blockers as concomitant therapy with other antihypertensive medications in a patient population with frequent coincident hypertension is important. Lastly, appropriate follow-up after the patient has been prescribed tamsulosin is essential in order to provide optimal patient care.

\section{Limitations}

It is possible that our evaluation was performed too soon after the posting of the drug use criteria and did not allow a sufficient time between the availability of the national criteria and implementation of the criteria at the participating facilities. Moreover, the dissemination procedures at that time merely provided for the notification of such guidance documents instead of providing the actual documents to the clinician. This created an extra step, requiring the clinician to search for the 


\section{Multicenter Drug Use Evaluation of Tamsulosin and Availability of Guidance Criteria for Nonformulary Use in the Veterans Affairs Health System}

document on the Internet, and therefore added an obstacle to timely adoption. Since the DUE involved convenience sampling, low- and high-use sites relative to the national average at the time of the DUE were represented, but averageuse sites were not measured. Therefore, we were unable to evaluate prescribing patterns from this important group. We did not determine the medical specialty of the prescribers and could therefore not analyze the difference in prescribing practices between urologists and primary care physicians.

It is also difficult to comment on whether the VA national average of $4.8 \%$ tamsulosin to total $\alpha$-blocker prescriptions at that time was appropriate, too low, or too high, as there were no existing benchmarks. While it was not an explicit objective of this study, information about the place in therapy for tamsulosin in the cost-effective treatment of BPH in VA patients is important. Our study suffered from incomplete data collection, a small number of study sites, patients lost to follow-up, and we did not obtain a thorough history of previous $\alpha$-blocker use (including the possibility that some patients received care outside of the VA system prior to receiving tamsulosin). Our study also used different clinicians to collect data in the 6 study sites, leading to possible variability in data abstraction from the medical charts. We also relied upon the information recorded in the patient medical charts and could not determine, for example, if the patients prescribed tamsulosin due to an ADE with a first-line nonselective $\alpha$-blocker actually experienced the ADE. Another limitation in our study stemmed from interclinician variability in that it was not possible to determine if the lack of a valid indication for tamsulosin was due to the absence of documentation of an acceptable indication or the documentation of an unacceptable indication for tamsulosin.

\section{Conclusion}

Simply making available the criteria for appropriate use of nonformulary $\alpha$-blocker had no measurable effect on the utilization of the target drug. Our results suggest that a multimodal approach that utilizes proven methods for changing prescribing patterns is necessary. Effective dissemination of the guideline for appropriate use of tamsulosin and adherence to the guideline could have saved nearly $\$ 2$ million in drug cost in 1 year.

\section{ACKNOWLEDGMENTS}

Investigators at the VA medical center study sites were Julio Lopez, PharmD; Andrew Capes, PharmD; Erin Schaefer, PharmD; Maurice Jones, PharmD; Kelley Curtis, PharmD, BCPS; and Paul Moreau, RPh.

\section{DISCLOSURES}

No outside funding supported this study. Authors Muriel Burk, Elaine Furmaga, Diane Dong, and Francesca Cunningham disclose no potential bias or conflict of interest relating to this article. Burk served as principal author of the study. Study concept and design were contributed by Burk, Cunningham, and Furmaga. Analysis and interpretation of data were contributed by Burk, Cunningham, Furmaga, and Dong; statistical expertise was contributed by Cunningham. Drafting of the manuscript was primarily the work of Burk and Furmaga, and its critical revision was the work of Dong and Cunningham

\section{REFERENCES}

1. Wilt TJ, MacDonald R, Nelson D. Tamsulosin for treating lower urinary tract symptoms compatible with benign prostatic obstruction: a systematic review of effectiveness and adverse effects. J Urol. 2002;167:177-83.

2. Schulman CC, Lock TM, Buzelin JM, Boeminghaus F, Stephenson TP, Talja $\mathrm{M}$, and the European Tamsulosin Study Group. Long-term use of tamsulosin to treat lower urinary tract symptoms/benign prostatic hyperplasia. J Urol. 2001;166:1358-63.

3. Narayan P, Lepor H. Long-term, open-label, phase III multicenter study of tamsulosin in benign prostatic hyperplasia. Urology. 2001;57:466-70.

4. Narayan P, Bruskewitz R. A comparison of two phase III multicenter, placebocontrolled studies of tamsulosin in BPH. Adv Ther. 2000;17:287-300.

5. Schulman CC, Cortvriend J, Jonas U, Lock TM, Vaage S, Speakman MJ, for the European Tamsulosin Study Group. Tamsulosin: 3-year long-term effectiveness and safety in patients with lower urinary tract symptoms suggestive of benign prostatic obstruction: analysis of a European, multinational, multicenter, open-label study. Eur Urol. 1999;36:609-20.

6. Narayan P, Tewari A, and members of the United States 93-01 Study Group. A second phase III multicenter placebo controlled study of 2 dosages of modified release tamsulosin in patients with symptoms of benign prostatic hyperplasia. J Urol. 1998;160:1701-06.

7. Lepor H, for the Tamsulosin Investigator Group. Long-term evaluation of tamsulosin in benign prostatic hyperplasia: placebo-controlled, double-blind extension of phase III trial. Urology. 1998;51:901-06.

8. Lepor $\mathrm{H}$, for the Tamsulosin Investigator Group. Phase III multicenter placebo-controlled study of tamsulosin in benign prostatic hyperplasia. Urology. 1998;51:892-900.

9. Abrams P, Schulman CC, Vaage S, for the European Tamsulosin Study Group. Tamsulosin, a selective $\alpha$ lc-adrenoceptor antagonist: a randomized, controlled trial in patients with benign prostatic "obstruction" (symptomatic BPH). Br J Urol. 1995;76:325-36

10. Wilt TJ, Howe W, MacDonald R. Terazosin for treating symptomatic benign prostatic obstruction: a systematic review of effectiveness and adverse effects. BJU Int. 2002;89:214-25.

11. Boyle P, Robertson C, Manski R, Padley RJ, Roehrborn CG. Meta-analysis of randomized trials of terazosin in the treatment of benign prostatic hyperplasia. Urology. 2001;58:717-22.

12. MacDiarmid SA, Emery RT, Ferguson SF, McGuirt-Franklin R, McIntyre WJ, Johnson DE. A randomized double-blind study assessing 4 versus $8 \mathrm{mg}$. doxazosin for benign prostatic hyperplasia. J Urol. 1999;162:1629-32.

13. Lepor H, Williford WO, Barry MJ, Haakenson C, Jones K. The impact of medical therapy on bother due to symptoms, quality of life and global outcome, and factors predicting response. Veterans Affairs Cooperative Studies Benign Prostatic Hyperplasia Study Group. J Urol. 1998;160:1358-67.

14. Mobley DF, Kaplan S, Ice K, Gaffney M, Dias N. Effect of doxazosin on the symptoms of benign prostatic hyperplasia: results from three double-blind placebo-controlled studies. Int J Clin Pract. 1997;51:282-88.

15. Kaplan SA, Soldo KA, Olsson CA. Terazosin and doxazosin in normotensive men with symptomatic prostatism: a pilot study to determine the effect of dosing regimen on effectiveness and safety. Eur Urol. 1995;28:223-28.

16. Chapple CR, Carter P, Christmas TJ et al. A three-month double-blind study of doxazosin as treatment for benign bladder outlet obstruction. $\mathrm{Br} \mathrm{J}$ Urol. 1994;74:50-56.

17. Holme JB, Christensen MM, Rasmussen PC, et al. 29-week doxazosin treatment in patients with symptomatic benign prostatic hyperplasia. Scand J Urol Nephrol. 1994;28:77-82.

18. Lepor H, Auerbach S, Puras-Baez A et al. A randomized, placebo-controlled multicenter study of the effectiveness and safety of terazosin in the treatment of benign prostatic hyperplasia. J Urol. 1992;148:1467-74.

19. Fabricius PG, Hannaford JM. Placebo-controlled study of terazosin in the treatment of benign prostatic hyperplasia with 2-year follow-up. Br J Urol. 1992;70(suppl 1):10-16. 
Multicenter Drug Use Evaluation of Tamsulosin and Availability of Guidance Criteria for Nonformulary Use in the Veterans Affairs Health System

20. Kirby RS, Coppinger SWC, Corcoran MO, et al. Prazosin in the treatment of prostatic obstruction. Br J Urol. 1987;60:136-42.

21. Hedlund H, Anderson KE, Ek A. Effects of prazosin in patients with benign prostatic obstruction. J Urol. 1983;130:275-78.

22. Djavan B, Marberger M. A meta-analysis on the effectiveness and tolerability of $\alpha_{1}$-adrenoreceptor antagonists in patients with lower urinary tract symptoms suggestive of benign prostatic obstruction. Eur Urol. 1999;36:1-13.

23. AUA Guidelines. Management of BPH (2003). Chapter 3: Results of the treatment outcome analyses. Available at: http://www.auanet.org/timssnet/ products/guidelines/main_reports/bph_management/chpat_3_appendix.pdf. Accessed November 13, 2003

24. Flomax (tamsulosin) [prescribing information]. Ridgefield, CT: Boehringer Ingelheim Pharmaceuticals, Inc; 1997.

25. The ALLHAT Officers and Coordinators for the ALLHAT Collaborative Research Group. Major cardiovascular events in hypertensive patients randomized to doxazosin vs. chlorthalidone: the Antihypertensive and Lipid-Lowering Treatment to Prevent Heart Attack Trial (ALLHAT). JAMA. 2000; 283:1967-75.
26. Hayes WC, Myers ER, Robinovitch SN, Van Den Kroonenberg A, Courtney AC, McMahon TA. Etiology and prevention of age-related hip fractures. Bone. 1996;18(suppl 1):77S-86S

27. Watson MC, Bond CM, Grimshaw JM, Mollison J, Ludbrook A, Walker AE. Educational strategies to promote evidence-based community pharmacy practice: a cluster randomized controlled trial (RCT). Fam Practice. 19(5):529-36.

28. Brown JB, Shye D, McFarland BH, Nichols GA, Mullooly JP, Johnson RE. Controlled trials of CQI and academic detailing to implement a clinical practice guideline for depression. Jt Comm J Qual Improv. 26(1):39-54.

29. Onion CW, Bartzokas CA. Changing attitudes to infection management in primary care: a controlled trial of active versus passive guideline implementation strategies. Fam Pract. 15(2):99-104.

30. Renders CM, Valk GD, Griffin S, Wagner EH, Eijk JThM van, Assendelft WJJ. Interventions to improve the management of diabetes mellitus in primary care, outpatient and community settings. Cochrane Database Syst Rev. 1, 2004.

31. Kassirer JP. The use and abuse of practice profiles. New Engl J Med. 1994:330:634-35. 